NASA Technical Memorandum 107024

AIAA-95-2470

6020

$\rho 10$

\title{
Combustion-Acoustic Stability Analysis for Premixed Gas Turbine Combustors
}

Douglas Darling

Lewis Research Center

Cleveland, Ohio

Krishnan Radhakrishnan

NYMA Inc.,

Brook Park, Ohio

Ayo Oyediran

AYT Corporation

$\begin{array}{lll}m & & \\ 0 & & 0 \\ n & n & 0 \\ m & 0 & n \\ 1 & u & 0 \\ n & 5 & 0 \\ z & 5 & 0\end{array}$

Brook Park, Ohio

Elizabeth Cowan

Iowa State University of Science and Technology

Ames, lowa

Prepared for the

31st Joint Propulsion Conference and Exhibit cosponsored by AIAA, ASME, SAE, and ASEE

San Diego, California, July 10-12, 1995

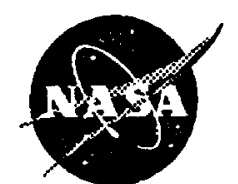

National Aeronautics and Space Administration

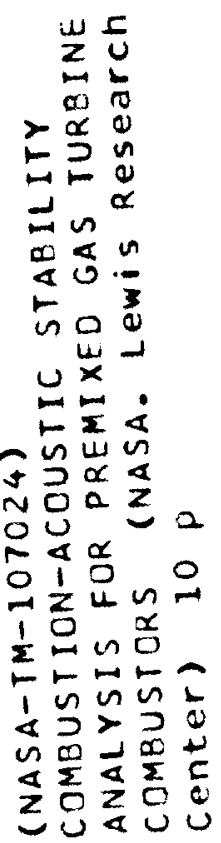





\title{
COMBUSTION-ACOUSTIC STABILITY ANALYSIS \\ FOR PREMIXED GAS TURBINE COMBUSTORS
}

\author{
Douglas Darling, NASA Lewis Research Center \\ Krishnan Radhakrishnan, NYMA Inc., NASA Lewis Research Center \\ Ayo Oyediran, AYT Corp. \\ Elizabeth Cowan, lowa State University
}

\begin{abstract}
Lean, prevaporized, premixed combustors are susceptible to combustion-acoustic instabilities. A model was developed to predict eigenvalues of axial modes for combustionacoustic interactions in a premixed combustor. This work extends previous work by including variable area and detailed chemical kinetics mechanisms, using the code LSENS. Thus the acoustic equations could be integrated through the flame zone. Linear perturbations were made of the continuity, momentum, energy, chemical species, and state equations. The qualitative accuracy of our approach was checked by examining its predictions for various unsteady heat release rate models. Perturbations in fuel flow rate are currently being added to the model.
\end{abstract}

\section{$\underline{\text { Introduction }}$}

Lean, prevaporized, premixed combustors are being considered for future low $\mathrm{NO}_{\mathrm{x}}$ engines. These combustors are susceptible to instabilities due to feedback between pressure fluctuations and combustion, causing damaging mechanical vibrations of the system, as well as degrading emissions characteristics and combustion efficiency. In a lean flame, blowout can also occur.

Many studies have been made on the interactions between acoustics and combustion for various applications, including liquid rockets, solid rockets, industrial gas turbines, aircraft gas turbines, pulse combustors, afterburners, and ramjet combustors; see Oyediran et al'. The current analysis adds to previous work by including detailed reaction mechanisms, multiple reflections and transmissions at the flame, and variable area.

The acoustics of the combustion chamber become a problem when the coupling of fluctuating heat release rate and pressure perturbations is concomitant with insufficient damping in the chamber and transmission at the boundaries to eliminate the amplification of acoustic energy due to the flame. Many factors affect the fluctuating heat release rate: (1) turbulence in the incoming flow, (2) fluctuations in the fuel delivery system (either caused by its own dynamics, or coupled with pressure fluctuations in the chamber), (3) variations in atomization and vaporization of the fuel and in fuel-air mixing, (4) hydrodynamic instability and vortex shedding at the flame holder, (5) variations in chemical kinetic reaction rates, (6) mean heat release rate, and (7) combustor type and geometry (e.g., premixed dump combustors and airblast spray combustors). All these factors are potentially important in a dynamic heat release rate model.

The turbulence in the incoming flow is invariably amplified by the flame (see Giammar and Putnam ${ }^{2,3}$ ). The noise tends to be broad band and does not necessarily cause acoustic resonances, although it could be the source of the oscillations amplified when an acoustic resonance does develop.

Fluctuations in the fuel flow rate into the flame have a direct effect on the fluctuating heat release rate. The fuel injection system may have its own resonant frequency, acting as a driving function to the heat release rate, or it may couple with the dynamics of the combustion chamber, in which case the fuel injection system is often represented by an admittance. The dynamics of the fuel delivery system is a concern for stability analyses of combustors ${ }^{4}$. 
In a combustor with a liquid reactant, the instantaneous rate at which reactants are delivered to the flame also depends upon the atomization, vaporization, and mixing rates. For liquid rockets, especially, these rates are important, because they often limit the burning rate ${ }^{5.6}$.

The dynamics of vortices and recirculation zones can affect the heat release rate, and are particularly important for premixed dump combustors. Large variations in the recirculation zones can cause separation of the boundary layer in the premixing region, leading to flashback?

The heat release rate can also change due to variations in the chemical kinetics of the combustion reaction. This factor becomes important when the time scale of the chemistry is of the same order as that of the chamber acoustics, or if the heat release is distributed over a length scale similar to that of the acoustics.

Which of the above effects become important is determined by the distribution of mean heat release rate, combustor type, and fuel type (i.e., gaseous or liquid).

The boundary conditions of the system are also important, because they determine how much of the acoustic energy leaves the combustion chamber. For rocket systems the admittance of a choked nozzle can be calculated $^{8}$. However, for other systems, the acoustic boundary conditions are often not so well defined. This is an area requiring additional investigation for gas turbine combustors. The present work, however, concentrates on the dynamics inside the combustion chamber and does not address boundary conditions in detail.

\section{Model}

A linear model was developed to predict the dynamics of a one-dimensional chemically reacting flow. The model can predict eigenvalues of acoustic resonances and standing wave patterns for resonance conditions. The advantages of the model include the use of detailed chemical reaction mechanisms and the ability to integrate the acoustic equations through the flame zone. Thus the needs to assume a thin reaction zone and specify phase and amplitude shifts at the flame front are eliminated. Instead, these quantities are simply calculated while integrating through the flame.

Solution variables are decomposed into mean (steady) and fluctuating components,

$$
p=\bar{p}+p^{\prime}, \quad T=\bar{T}+T^{\prime}, Q=\bar{Q}+Q^{\prime}, \text { etc. }
$$

where the overbar and prime denote mean and fluctuating quantities, respectively, and $p$ is the pressure, $T$ the temperature, and $Q$ the heat release rate per unit length.

Following the approach of Bloxsidge et al. ${ }^{9}$, the one-dimensional mean flow equations are as follows:

Continuity Equation

$$
\frac{d}{d x}(\bar{\rho} \bar{u} A)=0 .
$$

Momentum equation

$$
\bar{\rho} \bar{u} \frac{d \bar{u}}{d x}+\frac{d \bar{p}}{d x}=0 .
$$

Energy Equation

$$
\frac{d}{d x}\left[\bar{\rho} \bar{u} A\left(c_{p} \bar{T}+\frac{1}{2} \bar{u}^{2}\right)\right]=\bar{Q} \text {. }
$$

In these equations $x$ is the axial location, $\rho$ the density, $u$ the velocity, $A$ the cross-sectional area, and $c_{p}$ the constant-pressure, mass-specific heat of the mixture.

The fluctuating components were further separated into (1) a function of time $t\left(e^{\text {iwt }}\right.$, where $i=\sqrt{-1}$ and $\omega$ is the complex oscillation rate), to represent the frequency and growth/decay rate of oscillations and (2) a function of position, $\hat{p}(x)$. The latter function was itself decomposed into real and imaginary parts, to represent the phase and magnitude of the oscillations at each spatial location, for example,

$$
p^{\prime}=\hat{p}(x) e^{i \omega t},
$$

where

$$
\hat{p}(x)=p_{1}(x)+i p_{2}(x) .
$$


The functions $p_{1}(x)$ and $p_{2}(x)$ were determined by integrating the perturbed equations of state and mass, momentum, and energy conservation, equations $8-10$.

The temperature, pressure, density, velocity, and heat release rate were all perturbed, as described above. The perturbation in heat release rate, $Q^{\prime}$, is the energy source for amplification of acoustic waves as they propagate through the combustion zone:

$$
Q=\bar{Q}+Q^{\prime}=\bar{Q}+\hat{Q} e^{i \omega x} \text {. }
$$

The unsteady equations of mass, momentum, and energy conservation for linear perturbations of frequency $\omega$ are as follows:

$$
\begin{gathered}
\frac{d}{d x}(\hat{\rho} \bar{u} A+\bar{\rho} \hat{u} A)=-i \omega \hat{\rho} A, \\
(\hat{\rho} \bar{u}+\bar{\rho} \hat{u}) \frac{d \bar{u}}{d x}+\bar{\rho} \bar{u} \frac{d \hat{u}}{d x}+\frac{d \hat{\rho}}{d x}=-i \omega \bar{\rho} \hat{u},
\end{gathered}
$$

and

$$
\begin{gathered}
A \frac{d}{d x}\left[(\hat{\rho} \bar{u}+\bar{\rho} \hat{u})\left(c_{p} \bar{T}+\frac{1}{2} \bar{u}^{2}\right)+\bar{\rho} \bar{u}\left(c_{p} \hat{T}+\bar{u} \hat{u}\right)\right]= \\
\hat{Q}-i \omega A\left[\hat{\rho}\left(c_{v} \bar{T}+\frac{1}{2} \bar{u}^{2}\right)+\bar{\rho}\left(c_{v} \hat{T}+\bar{u} \hat{u}\right)\right] .
\end{gathered}
$$

The heat release rate was modeled as follows. At a given axial location the heat release rate per unit length is a function of the temperature, density, and composition at that point:

$$
Q=\bar{Q}+Q^{\prime}=f\left(T, \rho, \sigma_{i}\right), i=1, \ldots, N S,
$$

where $\sigma_{i}$ is the mass-specific mole number of species $i$, that is, number of moles of species $i$ per unit mass of mixture, and NS is the number of chemical species (reacting and inert). The perturbation in heat release rate was given by

$$
Q^{\prime}=\left(\frac{\partial Q}{\partial T}\right)_{P} T^{\prime}+\left(\frac{\partial Q}{\partial \rho}\right)_{T} \rho^{\prime} .
$$

A benefit of this approach is that for linear perturbations, the partial derivatives $\partial \mathrm{Q} / \partial \mathrm{T}$ and $\partial Q / \partial \rho$ are functions of position only, and not time. Therefore, they need to be calculated only once at each axial location for a given mean flow. These partial derivatives were determined using a modified version of LSENS, the Lewis Kinetics and Sensitivity Analysis Code ${ }^{10.11}$.

In addition to solving the ordinary differential equations (ODE's) for the mean reacting flow, LSENS generates the linear sensitivity coefficients $\left\{\partial y_{i} / \partial \eta_{j}\right\}$ and $\left\{\partial \dot{y}_{j} / \partial \eta_{j}\right\}$, where $y_{i}$ is a dependent variable (species mole number, temperature, etc.), $\dot{y}_{i}=d y / d t$, and $\eta_{j}$ is an independent parameter of interest (e.g., a rate coefficient parameter or an initial condition value). The sensitivity coefficients are obtained by solving their governing ODE's, by using the backward differentiation formula method, as implemented in the packaged code LSODE $^{12}$. Of particular relevance to the present work are the sensitivity coefficients $\left\{\partial \dot{q} / \partial \eta_{j}\right\}$, where $\dot{q}$ is the heat release rate per unit mass:

$$
\dot{q}=-\sum_{i=1}^{N A S} \dot{\sigma}_{i} h_{i} \text {. }
$$

Here NRS is the number of reacting species and $h_{i}$ the molar-specific enthalpy of species $i$. In the present model $\eta_{1}=T$ and $\eta_{2}=\rho$. If the effects of perturbations in fuel injection rate are also considered, equation (12) must include sensitivity coefficients with respect to the upstream fuel concentration, since it will change the local composition. The partial derivative $\partial \dot{q} / \partial \eta_{i}$, obtained simply by differentiating equation (13) with respect to $\eta_{i}$, is given by

$$
\frac{\partial \dot{q}}{\partial \eta_{i}}=-\sum_{i=1}^{N R S} \frac{\partial \dot{\sigma}_{i}}{\partial \eta_{j}} h_{i}-\sum_{i=1}^{N R S} \dot{\sigma}_{i} c_{p, i} \frac{\partial T}{\partial \eta_{i}},
$$

where $c_{\mathrm{p}, \mathrm{i}}$ is the constant-pressure, molar-specific heat of species i. Equation (14) is used to calculate the partial derivatives in equation (12), which, in turn, gives the heat release rate perturbation in equation (10).

\section{Results}

The linear stability model described in the previous section was used to determine complex eigenvalues for a simple combustor. These calculations were made in order to test the 
qualitative agreement of the model with combustion-acoustic theory. In our formulation, the real part of the eigenvalue represents the oscillation rate and the imaginary part the growth/decay rate. A positive imaginary component indicates disturbances will decay (i.e., a stable system), while a negative imaginary component indicates disturbances will grow (i.e., an unstable system).

We first present results for a constant-area combustor, and then examine the effects of variable area. All results presented herein were obtained with a premixed propane-air system and a fuel-air equivalence ratio of 0.9 . The propaneoxygen combustion chemistry was modeled with the mechanism of Jachimowski ${ }^{13}$. The reaction mechanism consisted of 85 reactions among 28 species, including the inert species $\mathrm{N}_{2}$ (i.e., reactions involving $\mathrm{N}_{2}$ were not considered).

The inlet state and flow geometry were as follows. The temperature and pressure were $1000 \mathrm{~K}$ and $5 \mathrm{~atm}$., respectively. The combustor length was $2 \mathrm{~m}$ and the inlet velocity $100 \mathrm{~m} / \mathrm{s}$. The flame was stabilized by assuming that a flameholder would increase the residence time, thereby enabling the combustion reaction to occur. However, the full area (i.e., ignoring flameholder blockage) and resultant velocity were used for the acoustic calculations. The flow conditions used in this work are summarized in Table 1.

The present study used the boundary conditions $u^{\prime}=0$ and $\mathrm{dp}^{\prime} / \mathrm{dx}=0$ at the walls. If the mean flow Mach number were small, these boundary conditions would represent acoustically hard walls at the boundaries. For a nonnegligible Mach number, however, $d p^{\prime} / d x=0$ is not the condition for complete reflection, for which the

TABLE 1.-CONDITIONS FOR ONEDIMENSIONAL FLOW COMBUSTIONACOUSTIC CALCULATIONS

\begin{tabular}{ll}
\hline Fuel & Propane \\
Flame Type & Premixed \\
Equivalence ratio & 0.9 \\
Inlet temperature & $1000 \mathrm{~K}$ \\
Inlet pressure & $5 \mathrm{~atm}$. \\
Inlet velocity & $100 \mathrm{~m} / \mathrm{s}$ \\
Combustor length & $2 \mathrm{~m}$ \\
\hline
\end{tabular}

magnitude of $d p^{\prime} / d x$ of the wave traveling with the flow will be smaller than that of the wave traveling against it (for the same amplitude and phase angle).

The model can accept any user-supplied admittance as a boundary condition. However, the goal of our work was to show that the model is in qualitative agreement with theory. Therefore, the boundary conditions are not particularly important for the present study. They will, however, become important when the model predictions are compared with experimental data.

The grid spacing (i.e., step size) used to integrate the ODE's is automatically selected by LSODE. The variation of the spacing with axial position is shown in Figure 1 for the conditions given in table 1 and constant area. Note that the grid spacing was small in regions where the mean flow quantities varied rapidly. The step size pattern produces a chemical kinetics solution that satisfies prescribed accuracy requirements ${ }^{10,12}$, thereby enabling the linear perturbation model to integrate the governing ODE's through the flame region. Figures 2 and 3 show the mean flow temperature and Mach number distributions, respectively, for the conditions given in table 1.

Various models were used for the fluctuating heat release rate, $Q^{\prime}$, in order to validate the results qualitatively. It was first set equal to zero, to determine the eigenvalues for the passive system (i.e., the flame does not add acoustic energy). Then, the fluctuating heat release rate was modeled (1) as a real constant

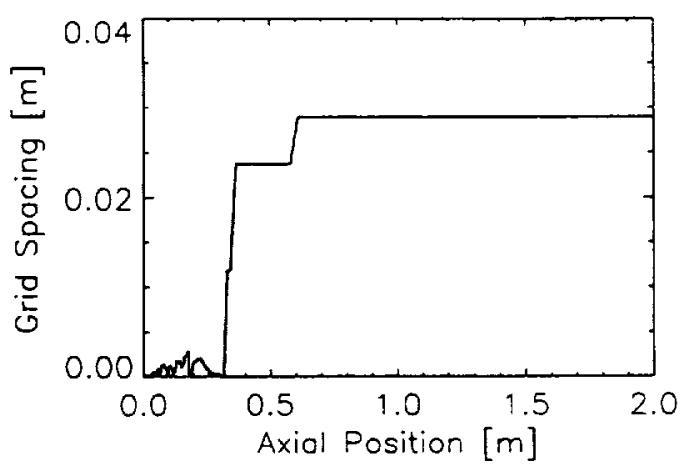

Figure 1.-Grid spacing selected by chemical kinetics code LSENS for conditions given in table 1 and constant area. 


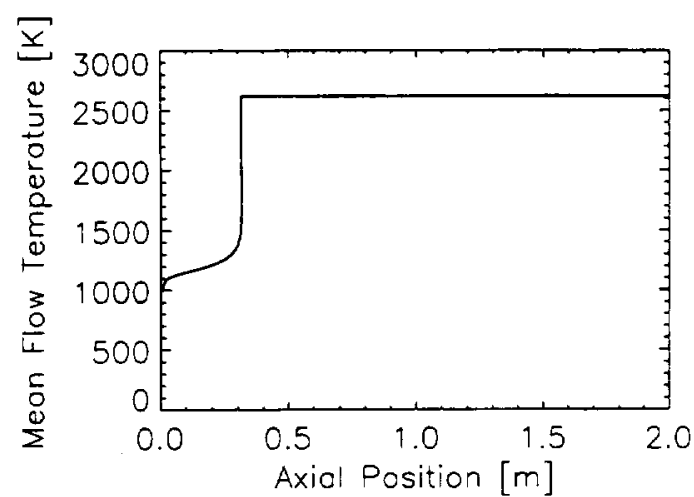

Figure 2.-Axial distribution of mean flow temperature for conditions given in table 1 and constant area.

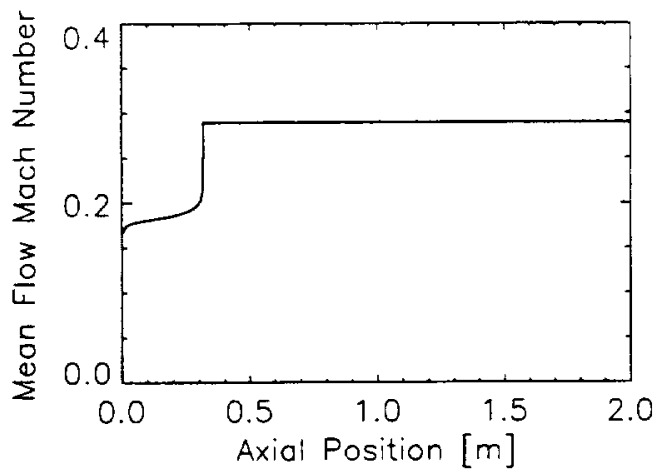

Figure 3.-Axial distribution of mean flow Mach number for conditions given in table $i$ and constant area.

times the pressure perturbation (i.e., in phase with pressure), (2) as an imaginary constant times the pressure perturbation (i.e., $\pi / 2$ radians out of phase with pressure), (3) as a real constant times the velocity perturbation (i.e., in phase with velocity), and (4) using the perturbations in the chemistry from equation 12 , as described in the previous section.

Eigenvalues were calculated for these heat release rate models; their real and imaginary components are shown in Figure 4. For each point in this figure, table 2 gives the corresponding fluctuating heat release rate model; here $c_{1}$ and $c_{2}$ are real positive constants.

Points $A$ and $B$ represent the two lowest frequency axial modes for the passive system using the mean flow conditions shown in Figures 2 and 3 . The standing wave pattern for pressure

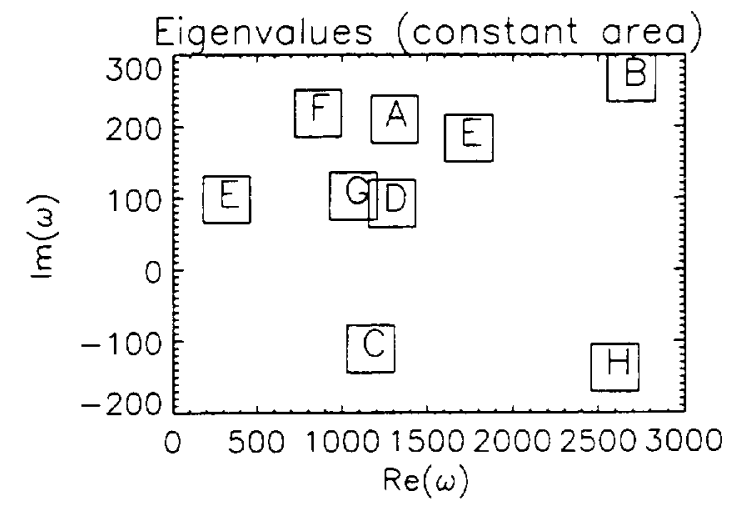

Figure 4.-Eigenvalues for flow conditions given in table 1, constant area, and dynamic heat release rate models described in table 2.

TABLE 2.-FLUCTUATING HEAT RELEASE RATE MODELS USED IN FIGURES 4 AND 8

\begin{tabular}{ll}
\hline Point & $\begin{array}{c}\text { Fluctuating Heat } \\
\text { Release Rate Model }\end{array}$ \\
\hline A & $Q^{\prime} / \bar{Q}=0$ \\
$B$ & $Q^{\prime} / \bar{Q}=0$ \\
C & $Q^{\prime} / \bar{Q}=c, p^{\prime}$ \\
$D$ & $Q^{\prime} / \bar{Q}=\frac{1}{3} c, p^{\prime}$ \\
$E$ & $Q^{\prime} / \bar{Q}=i c, p^{\prime}$ \\
$F$ & $Q^{\prime} / \bar{Q}=c_{2} u^{\prime}$ \\
$G$ & $Q^{\prime} / \bar{Q} \rightarrow$ Eq. 12 \\
$H$ & $Q^{\prime} / \bar{Q} \rightarrow$ Eq. 12 \\
I & $Q^{\prime} / \bar{Q}=0$ \\
$J$ & $Q^{\prime} / \bar{Q}=0$ \\
$K$ & $Q^{\prime} / \bar{Q} \rightarrow$ Eq. 12 \\
L & $Q^{\prime} / \bar{Q} \rightarrow$ Eq. 12
\end{tabular}

and velocity for the first mode (point A) are shown in Figure 5. This mode is nominally a half wavelength mode. However, since the mean flow has a significant velocity relative to the speed of sound and since there is a phase shift in the standing velocity wave near the flame, the standing wave is not exactly a half wavelength of the traveling waves.

The imaginary part of $\omega$ represents the growth/decay rate of the resonance. For the passive case (point A) the imaginary part of $\omega$ is $210 \mathrm{~s}^{-1}$, indicating that the oscillation is decaying. This is an important test of the model, since a 


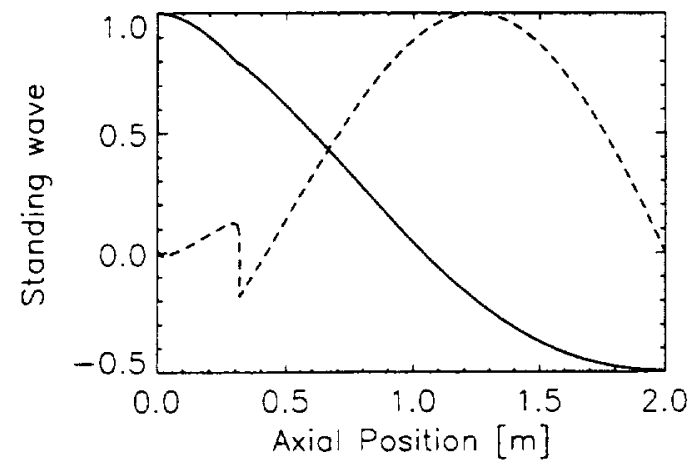

Solid Line: normalized pressure Dashed Line: normalized velocity

Figure 5.-Standing wave pattern for lowest frequency mode for constant area and passive case $\left(Q^{\prime}=0\right)$.

passive system cannot have a negative imaginary part of $\omega$. The decay of the oscillation is caused by energy lost at the boundaries (recall that $\mathrm{dp} / \mathrm{dx}$ $=0$ does not represent complete reflection when the Mach number is nonnegligible). When the model was applied to small Mach number flows, the imaginary part of $\omega$ approached zero for the passive case.

Simple models of the fluctuating heat release rate were tested, in order to evaluate the model qualitatively. First, the heat release rate was described as a constant times the pressure perturbation, that is, $Q^{\prime}=c_{1} p^{\prime}$. The specified value for the constant $c_{1}$ was large enough to cause a significant change in the eigenvalues of the system, relative to the passive case results. The new lowest frequency eigenvalue is shown as point $C$ in Figure 4. The imaginary part of $\omega$ decreased (i.e., the system became more unstable), when the fluctuating heat release rate was in phase with the pressure. This result is consistent with the Rayleigh criterion, and represents another important qualitative check of the model. The constant was then reduced to a third of its original value, in order to examine if the change in the growth rate of disturbances varied proportionally. The eigenvalue for the reduced constant is point $D$. The growth rate did not vary linearly with $c_{1}$.
Next, the fluctuating heat release rate was modeled as a purely imaginary constant times the pressure perturbation (i.e., the heat release rate was $\pi / 2$ radians out of phase with the pressure). In this case two eigenvalues were obtained with frequencies similar to or less than those for the passive case. Both eigenvalues are labeled $E$ in figure 4 . This model for the fluctuating heat release rate should not add or subtract acoustic energy from the system, but only shift the phase. If there were no acoustic energy loss at the boundaries, we would expect the imaginary part of $\omega$ to be zero for both the passive and active systems. Since there is a change in the acoustic energy lost at the boundaries as the frequency changes, there is a change in the decay rate of the disturbances when the heat release rate is modeled by this procedure.

Point $F$ represents the eigenvalue when the fluctuating heat release rate was in phase with the velocity perturbation, that is, $Q^{\prime}=c_{2} u^{\prime}$. This representation of the heat release rate resulted in a smaller effect on the stability of the system than did the case $Q^{\prime}$ equal to a function of $p^{\prime}$. This finding is to be expected, inasmuch as the standing velocity wave is far from being in phase with the standing pressure wave. If boundary conditions that caused the pressure and velocity to be in phase were selected, the results for this heat release rate model would parallel those for points $C, D$, and $E$.

The last heat release rate model used the perturbations in chemistry described in the previous section. Point $G$ is the eigenvalue for the first mode. Figure 6 shows the corresponding pressure and velocity standing waves.

The second mode was also considered. Point $B$ is the passive case $\left(Q^{\prime}=0\right)$ and point $H$ the active case, that is, using the chemistry model. For the latter case the system was unstable (negative imaginary part of $\omega$ ); the pressure and velocity standing waves are given in figure 7.

As final checks of the model, the effects of variable area were studied. The same flow conditions specified previously (see table 1) were used, but the duct area varied as follows:

$$
\frac{A(x)}{A(0)}=1+0.1 x
$$




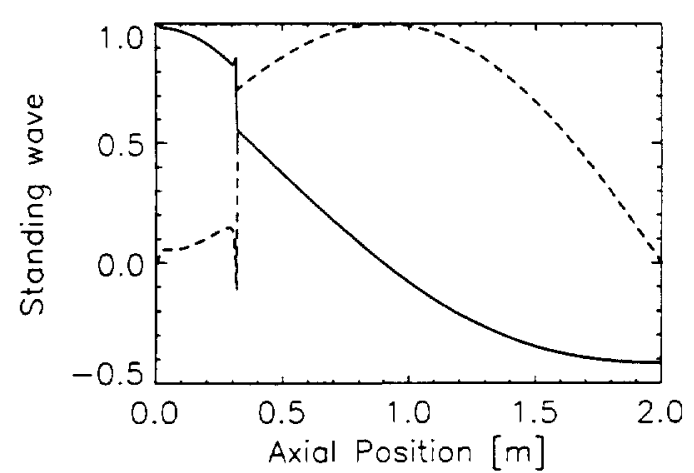

Solid Line: normalized pressure Dashed Line: normalized velocity

Figure 6.-Standing wave pattern for lowest frequency mode for constant area and active case ( $Q^{\prime}$ from equation 12).

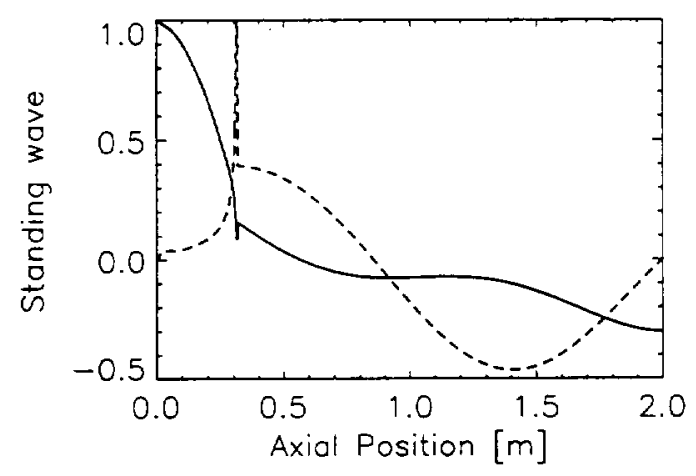

Solid Line: normalized pressure Dashed Line: normalized velocity

Figure 7.-Standing wave pattern for second lowest frequency mode for constant area and active case $\left(Q^{\prime}\right.$ from equation 12).

where $A(0)$ is the combustor inlet area and $A(x)$ the area at axial position $x$. Thus, there was a $20 \%$ increase in area along the 2 meter long combustor. This change in area, of course, changes the mean flow quantities. Therefore, LSENS had to be used to calculate the new values for the mean flow variables and the partial derivatives $\partial Q / \partial \rho$ and $\partial Q / \partial T$ at each axial location. The eigenvalues for the first two modes are shown in figure 8 . Points $I$ and $\mathrm{J}$ represent the passive case $\left(Q^{\prime}=0\right)$, while points $K$ and $L$

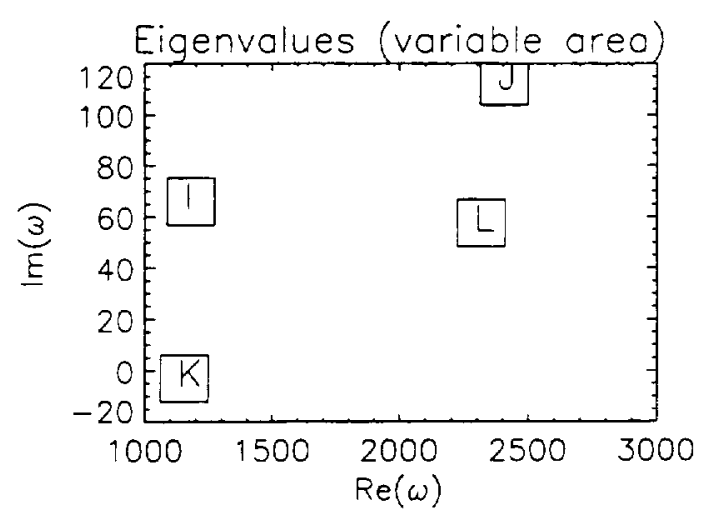

Figure 8.-Eigenvalues for variable-area flow conditions and dynamic heat release rate models described in table 2 .

represent the model of $Q^{\prime}$ using equation 12 . Once again the amplification of the acoustic disturbances by the dynamic heat release rate caused the imaginary part of $\omega$ to become more negative, indicating increasing system instability. For the variable-area case, the unsteady heat release due to the propane chemistry had a greater effect on the first mode than on the second. In contrast, the constant-area case displayed the opposite behavior (see figure 4).

\section{Conclusions}

A detailed chemical kinetics mechanism was successfully included in a linear stability model for one-dimensional reacting flow. By perturbing the chemical kinetic rates, the model was shown to predict qualitatively correct feedback between combustion and acoustics. When the pressure was in phase with the unsteady heat release rate, the system became less stable, which is consistent with the Rayleigh criterion. In addition, perturbations in chemical kinetic rates tended to make the system less stable.

The model is being improved to incorporate fuel flow rate fluctuations, which must be included before the theoretical predictions can be compared with experimental results. Varying the fuel flow rate will produce perturbations in the local composition. By using detailed chemistry, the attendant perturbations in flame location and heat release rate can be modeled accurately. 


\section{Acknowledgments}

This work was supported by the High Speed Research Program, NASA-Lewis Research Center, Cleveland, $\mathrm{OH}$.

\section{References}

[1] Oyediran, A., Darling, D., and Radhakrishnan, K., "Review of Combustion Acoustic Instabilities," AIAA Paper 95-2469, 1995.

[2] Giammar, R.D. and Putnam, A.A., "Noise Generation by Turbulent Flames," American Gas Association, Inc., Catalog No. M00080, 1971.

[3] Giammar, R.D. and Putnam, A.A., "Combustion Roar of Premix Burners, Singly and in Pairs," Combust. Flame, Vol. 18, 1972, pp. 435-438.

[4] Feiler, C.E. and Heidmann, M.F., "Dynamic Response of Gaseous-Hydrogen Flow System and Its Application to High-Frequency Combustion Stability," NASA TN D-4040, 1967.

[5] Heidmann, M.F. and Weiber, P.R., "Analysis of Frequency Response Characteristics of Propellant Vaporization," NASA TN D-3749, 1966.

[6] Vingert, L., and Borghi, R., "Injection, Atomisation, Spray Vaporisation and Combustion," in Combustion Instability in Liquid Rocket Engines, Schöyer, H.F.R., ed., ESA-WPP-062, 1993.
[7] Keller, J.O., Vaneveld, L., Ghoniem, A.F., Daily, J.W., Oppenheim, A.K., Korschelt, D., and Hubbard, G.L., "Mechanism of Instabilities in Turbulent Combustion Leading to Flashback," AIAA Paper 81-0107, 1981.

[8] Crocco, L. and Sirignano, W.A., "Behaviour of Supercritial Nozzles under Three-Dimensional Oscillatory Conditions," AGARDOGRAPH 117, North Atlantic Treaty Organization, 1967.

[9] Bloxsidge, G.J., Dowling, A.P., Hooper, N., and Langhorne, P.J., "Active Control of Reheat Buzz," AIAA J., Vol. 26, 1988, pp. 783-790.

[10] Radhakrishnan, K., "LSENS-A General Chemical Kinetics and Sensitivity Analysis Code for Homogeneous Gas-Phase Reactions.

I. Theory and Numerical Solution Procedures", NASA RP-1328, 1994.

[11] Radhakrishnan, K. and Bittker, D.A., "LSENS-A General Chemical Kinetics and Sensitivity Analysis Code for Homogeneous GasPhase Reactions. II. Code Description and Usage", NASA RP-1329, 1994.

[12] Radhakrishnan, K. and Hindmarsh, A.C., "Description and Use of LSODE, the Livermore Solver for Ordinary Differential Equations, "NASA RP-1327, Lawrence Livermore National Laboratory Report UCRL-ID-113855, 1993.

[13] Jachimowski, C. J., "Chemical Kinetic Reaction Mechanism for the Combustion of Propane", Combust. Flame, Vol. 55, 1984, pp. 213-224. 


\begin{tabular}{|c|c|c|c|c|}
\hline \multicolumn{3}{|c|}{ REPORT DOCUMENTATION PAGE } & & $\begin{array}{l}\text { Form Approved } \\
\text { OMB No. } 0704-0188\end{array}$ \\
\hline \multicolumn{5}{|c|}{ 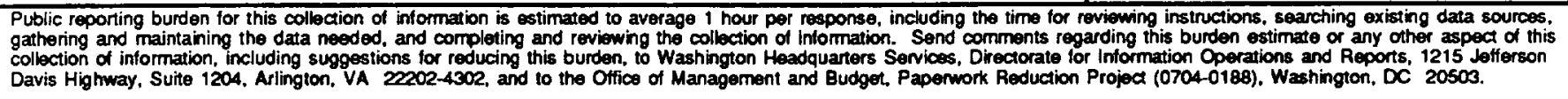 } \\
\hline 1. AGENCY USE ONLY (Leave blank) & $\begin{array}{r}2 \text { REPORT DATE } \\
\text { August } 1995\end{array}$ & \multicolumn{3}{|c|}{$\begin{array}{l}\text { 3. REPORT TYPE AND DATES COVERED } \\
\text { Technical Memorandum }\end{array}$} \\
\hline \multicolumn{3}{|c|}{$\begin{array}{l}\text { 4. TTLE AND SUBTITE } \\
\text { Combustion-Acoustic Stability Analysis for Premixed Gas Turbine Combustors }\end{array}$} & \multirow{2}{*}{\multicolumn{2}{|c|}{$\begin{array}{l}\text { 5. FUNDING NUMBERS } \\
\text { WU-537-02-21 } \\
\text { NAS3-27186 } \\
\text { NAS3-27571 }\end{array}$}} \\
\hline \multicolumn{3}{|c|}{$\begin{array}{l}\text { 6. AUTHOR(S) } \\
\text { Douglas Darling, Krishnan Radhakrishnan, Ayo Oyediran, and Elizabeth Cowan }\end{array}$} & & \\
\hline \multicolumn{3}{|c|}{$\begin{array}{l}\text { 7. PERFORMING ORGANIZATION MAME(S) AND ADDRESS(ES) } \\
\text { National Aeronautics and Space Administration } \\
\text { Lewis Research Center } \\
\text { Cleveland, Ohio } 44135-3191\end{array}$} & \multicolumn{2}{|c|}{$\begin{array}{l}\text { 8. PERFORMING ORGANIZATION } \\
\text { REPORT NUMBER }\end{array}$} \\
\hline \multicolumn{3}{|c|}{ 9. SPONSORING/MONITORING AGENCY NAME(S) AND ADDRESS(ES) } & 10. SP & $\begin{array}{l}\text { NSORING/MONTTORING } \\
\text { NCY REPORT NUMBER } \\
\text { SA TM-107024 } \\
\text { A-95-2470 }\end{array}$ \\
\hline \multicolumn{5}{|c|}{$\begin{array}{l}\text { 11. SUPPLEMENTARY NOTES } \\
\text { Prepared for the 31st Joint Propulsion Conference and Exhibit cosponsored by AIAA, ASME, SAE, and ASEE, San } \\
\text { Diego, California, July 10-12, 1995. Douglas Darling, NASA Lewis Research Center; Krishnan Radhakrishnan, NYMA } \\
\text { Inc., 2001 Aerospace Parkway, Brook Park, Ohio } 44142 \text { (work funded by NASA Contract NAS3-27186); Ayo Oyediran, } \\
\text { AYT Corporation, } 2001 \text { Aerospace Parkway, Brook Park, Ohio } 44142 \text { (work funded by NASA Contract NAS3- 27571); } \\
\text { and Elizabeth Cowan, Iowa State University of Science and Technolgy, Ames, Iowa 50010. Responsible person, Douglas } \\
\text { Darling, organization code 2710, (216) 433-8273. }\end{array}$} \\
\hline \multirow{2}{*}{\multicolumn{3}{|c|}{$\begin{array}{l}\text { 12a. DISTAIBUTION/AVAILABILTY STATEMENT } \\
\text { Unclassified - Unlimited } \\
\text { Subject Categories } 07,64 \text {, and } 34 \\
\text { This publication is available from the NASA Center for Aerospace Information, (301) 621-0390. }\end{array}$}} & \multirow{2}{*}{\multicolumn{2}{|c|}{ 12b. DISTRIBUTION CODE }} \\
\hline & & & & \\
\hline \multicolumn{5}{|l|}{ 13. ABSTRACT (Maximum 200 words) } \\
\hline \multicolumn{5}{|c|}{$\begin{array}{l}\text { Lean, prevaporized, premixed combustors are susceptible to combustion-acoustic instabilities. A model was developed } \\
\text { to predict eigenvalues of axial modes for combustion-acoustic interactions in a premixed combustor. This work extends } \\
\text { previous work by including variable area and detailed chemical kinetics mechanisms, using the code LSENS. Thus the } \\
\text { acoustic equations could be integrated through the flame zone. Linear perturbations were made of the continuity, } \\
\text { momentum, energy, chemical species, and state equations. The qualitative accuracy of our approach was checked by } \\
\text { examining its predictions for various unsteady heat release rate models. Perturbations in fuel flow rate are currently } \\
\text { being added to the model. }\end{array}$} \\
\hline \multirow{2}{*}{\multicolumn{4}{|c|}{$\begin{array}{l}\text { 14. SUBJECT TERMS } \\
\text { Combustion; Combustion stability; Acoustics; Chemical kinetics; Numerical analysis }\end{array}$}} & $\begin{array}{c}\text { 15. NUMBER OF PAGES } \\
10\end{array}$ \\
\hline & & & & $\begin{array}{r}\text { 16. PAICE CODE } \\
\text { A02 }\end{array}$ \\
\hline $\begin{array}{l}\text { 17. SECURTY CLASSIFICATION } \\
\text { OF REPORT } \\
\text { Unclassified }\end{array}$ & $\begin{array}{l}\text { 18. SECURITY CLASSIFICATION } \\
\text { OF THIS PAGE } \\
\text { Unclassified }\end{array}$ & $\begin{array}{l}\text { 19. SECURITY CLASSIFICA } \\
\text { OF ABSTRACT } \\
\text { Unclassified }\end{array}$ & ATION & 20. LIMTTATION OF ABSTRACT \\
\hline
\end{tabular}


